\title{
OS CURSOS SUPERIORES DE TECNOLOGIA NO CONTEXTO DE EXPANSÃO DA EDUCAÇÃO SUPERIOR NO BRASIL: A RETOMADA DA ENFASE NA EDUCAÇÃO PROFISSIONAL
}

\author{
JULIANA FAVRETTO* \\ Cleide FÁtima MoretTo*
}

\begin{abstract}
RESUMO: O artigo analisa a expansão e o comportamento da oferta dos cursos superiores de tecnologia no âmbito da educação superior brasileira. Resgata a origem da educação profissional, das legislações e ações públicas que constituíram o processo de desenvolvimento da educação superior tecnológica no Brasil. Apresenta evidências da estrutura da oferta de cursos superiores de tecnologia, em nível de categoria acadêmica, administrativa e distribuição regional, no período de 2000 a 2010, um recorte de dados secundários extraídos do banco de dados do Inep/MEC. Os dados revelam que houve uma expansão substancial dos cursos superiores de tecnologia no período analisado, quando comparados aos demais cursos de graduação, com maior ênfase no setor privado e no âmbito acadêmico das universidades.
\end{abstract}

Palavras-chave: Educação profissional. Cursos superiores de tecnologia. Educação superior brasileira.

\section{TECHNOLOGICAL HIGHER EDUCATION COURSES IN THE CONTEXT OF EXPANDING HIGHER EDUCATION IN BRAZIL: RESUMING THE EMPHASIS ON PROFESSIONAL EDUCATION}

ABSTRACT: The article analyzes the expansion and the supply behavior of technological higher education courses in the context of higher education in Brazil. It traces the origins of vocational education, laws and public actions that constituted the development process of technological higher education in Brazil. It presents evidence of the supply structure of technological higher education courses, at the academic, administrative and regional distribution levels in the period 2000 to 2010, as well as some secondary data

\footnotetext{
* Mestre em Educação e servidora pública do Instituto Federal Sul-Riograndense (Ifsul, Passo Fundo). E-mail: juliana.favretto@passofundo.ifsul.edu.br

** Doutora em Teoria Econômica e professora titular da Faculdade de Ciências Econômicas da Universidade de Passo Fundo (UPF). E-mail: moretto@upf.br
} 
from Inep/MEC's database. The data reveal that there has been a substantial expansion of technological higher education courses over this period, when compared to other courses, with greater emphasis on the private sector and on the academic realm of universities.

Key words: Professional education. Technological higher education courses. Brazilian higher education.

LES COURS SUPÉRIEURS DE TECHNOLOGIE DANS LE CONTEXTE D'EXPANSION DE L'ENSEIGNEMENT SUPÉRIEUR AU BRÈSIL:

LA REPRISE SUR LA FORMATION PROFESSIONNELLE

RÉSUMÉ: L'article analyse l'expansion et le comportement de l'offre des cours supérieurs de technologie dans le contexte de l'enseignement supérieur brésilien. Il reprend l'origine de la formation professionnelle, des législations et des actions publiques qui ont constitué le processus de développement de l'enseignement technologique supérieur au Brésil. Il présente des évidences de la structure de l'offre de cours technologiques, dans le cadre de la distribution académique, administrative et régionale dans la période de 2000 à 2010, un découpage de données secondaires à partir de bases de données de l'Institut National d'Études et de Recherches (Inep) et du Ministère de l'Éducation et de la Culture (MEC). Les données révèlent qu'il a y eu une expansion considérable des cours supérieurs de technologie dans la période analysée, quand comparés aux autres formations diplômantes, en insistant davantage sur le secteur privé et dans le cadre de l'enseignement supérieur.

Mots-clés: Formation professionnelle. Cours supérieurs de technologie. L'enseignement supérieur brésilien.

\section{Introdução}

A educação superior, no contexto educacional brasileiro, tem passado por transformações e remodelações importantes nos últimos anos. Muitas destas envolveram, e envolvem, a educação profissional na perspectiva da educação tecnológica. Os cursos superiores de tecnologia são, legalmente, cursos regulares de graduação, regulamentados pelas Diretrizes Curriculares Nacionais estabelecidas pelo Conselho Nacional de Educação e focados no domínio e na aplicação de conhecimentos científicos e tecnológicos em áreas de conhecimentos relacionados a uma ou mais áreas profissionais. Tais cursos têm o objetivo de promover o desenvolvimento de competências profissionais que possibilitem a utilização da tecnologia.

$\mathrm{O}$ acesso aos cursos superiores de tecnologia enquadra-se no campo teórico da educação profissional. Por educação profissional entende-se uma vasta gama de processos educativos, de formação e de treinamento em instituições e modalidades variadas, que contemplam a formação técnica do estudante, tanto em nível médio quanto superior, por meio de cursos ofertados tanto por instituições formais de ensino, como por organizações patronais que compõem o sistema " $S$ ", organizações 
sindicais, comunitárias ou não governamentais (CHRISTOPHE, 2010). Educação profissional, ensino técnico, ensino profissionalizante, formação profissional, capacitação profissional e qualificação profissional são termos que costumam ser utilizados indistintamente, na literatura e na prática, referindo-se tanto ao ensino ministrado nas instituições públicas e escolas regulares, quanto a quaisquer processos de capacitação da força de trabalho, de jovens e adultos. Eles são ministrados por uma ampla variedade de cursos técnicos, de formação ou de treinamento, com natureza, duração e objetivos diferenciados.

Estudos que tratam da formação da educação superior no país revelam que, por muito tempo, as universidades afirmaram-se como instituições educacionais por excelência na formação do pensamento de elites, bem como na produção do conhecimento científico e no desenvolvimento cultural em geral. Contudo, o aumento da exigência de titulação em nível superior para o ingresso no mercado de trabalho, a necessidade de dirigir-se a um público cada vez mais heterogêneo e a capacitação requerida pelo mercado de trabalho têm levado as instituições de ensino superior a ofertar cursos em novos campos profissionais, com enfoque nas transformações tecnológicas (NEVES, 2004; KUENZER, 1995). As mudanças observadas no cenário econômico e produtivo, em nível mundial, sinalizam a utilização de tecnologias complexas agregadas à produção e à prestação de serviços, requerendo sólida educação formal para todos os trabalhadores.

Nesse contexto, a Lei de Diretrizes e Bases da Educação (LDB), promulgada e publicada em 1996, representa o marco legal básico de uma política educacional que buscou dar conta da realidade desencadeada por um processo de reformulação profunda na educação superior. Nesse sentido, a LDB se coloca como uma tentativa de superar os enfoques de uma educação apenas voltada à qualificação para desenvolver competências para o trabalho, dispondo como diretriz básica que a educação profissional deve ser integrada às diferentes formas de educação, ao trabalho, à ciência e à tecnologia, com vistas ao permanente desenvolvimento do país (BRASIL, 1996). O pressuposto teórico, portanto, é de que, no contexto econômico e social contemporâneo e local, a proliferação da oferta de cursos superiores de tecnologia no Brasil pode ser um indicativo de um estágio de mudanças na história da educação profissional brasileira.

O presente artigo tem por objetivo geral analisar a expansão e o comportamento da oferta dos cursos superiores de tecnologia no âmbito da educação superior e das políticas educacionais brasileiras. Especificamente, propõe resgatar a origem da educação profissional, das legislações e ações públicas que consolidaram a educação superior tecnológica no Brasil. Busca, também, apresentar as características gerais da oferta dos cursos superiores de tecnologia no que diz respeito ao enquadramento acadêmico, administrativo e de distribuição regional, no período de 2000 
a 2010. Para tanto, baseia-se na análise dos documentos que normatizam a estrutura da educação superior em geral e da educação tecnológica, especificamente. De forma aplicada, apresenta um recorte de dados secundários extraídos do banco de dados do Instituto Nacional de Estudos e Pesquisas Educacionais Anísio Teixeira (Inep/ MEC), os quais foram tratados por meio de análise estatística descritiva simples.

As seções que seguem tratam, no intuito de fomentar o debate, da educação superior tecnológica no âmbito da expansão do ensino superior brasileiro e das reformas educacionais, da retomada e das novas configurações identificadas no que tange aos cursos superiores de tecnologia. Apresentam evidências recentes da estrutura de oferta dos cursos superiores de tecnologia no Brasil e, por fim, elenca algumas considerações finais.

\section{Educação superior tecnológica, reformas educacionais e expansão do ensino superior brasileiro}

No período em que o país viveu sob o regime militar, como argumenta Cunha (1988), o ensino superior sofreu várias influências do modelo norte-americano de universidade, o que provocou mudanças radicais na organização dos recursos humanos e materiais das instituições, incluindo a participação da iniciativa privada.

Para a mudança do modelo universitário, todavia, era necessário alterar a legislação que o regulava. Então, em 1968, foi implantada a Reforma Universitária (Lei n. 5.540), que, entre outras definições, propunha a instalação e o funcionamento de "cursos profissionais de curta duração", destinados a propiciar habilitações intermediárias de grau superior. Esses seriam ministrados em universidades e em outros estabelecimentos de educação superior em funcionamento no país. Nesse período surgem os cursos superiores de tecnologia (BRASIL, 1968). Como argumenta Rossato (2005), o governo brasileiro criou mecanismos para a expansão do ensino superior, favorecendo a criação de instituições de ensino superior (IES) não apenas em cidades de grande porte, mas também no interior. O resultado, segundo ele, foi a expansão da oferta, sobretudo por instituições particulares e de estabelecimentos isolados em todo território nacional.

Na década de 1990, entretanto, à luz das tendências neoliberais, observou-se a reordenação do Estado brasileiro, a qual, no que tange à educação, culminou, em 1996, com a promulgação da LDB. Ainda que a noção de formação do ser humano integral esteja presente nas diretrizes básicas da LDB, ao definir as diferentes finalidades do ensino superior, podemos dizer que as reformas embasaram-se nas mudanças econômicas impostas pela globalização, que exigia maior eficiência e produtividade dos trabalhadores. A titulação acadêmica, por sua vez, estabeleceria a vinculação do 
indivíduo ao mercado de trabalho, num cenário produtivo estratificado, o que pode ser evidenciado pelo aumento significativo na demanda por ensino de nível superior no país (SUBIRATS, 2000).

Com a mudança de governo, a partir de 2003, retomaram-se os debates para promover mais uma reforma no ensino superior. Nesse contexto, foram sancionadas algumas leis que colaboraram na definição dos rumos da educação superior e da aproximação desta com o mercado (BRASIL, 2004b). Foram implementadas medidas no sentido de promover projetos de inovação e pesquisa científica e tecnológica no ambiente produtivo, por meio de parcerias entre universidades e empresas, com vistas à capacitação e ao alcance da autonomia tecnológica e ao desenvolvimento industrial do país. Ainda, para assegurar a qualidade da educação superior, foi instituído o Sistema Nacional de Avaliação da Educação Superior (Sinaes), ${ }_{1}^{1}$ apresentando uma nova proposta avaliativa, com ênfase em dimensões que vão para além do ensino, da pesquisa e da extensão, e criando mecanismos de avaliação concomitantes para as instituições, os cursos de graduação e os alunos integrantes deste sistema. Complementarmente, o governo federal adotou alguns mecanismos para viabilizar o acesso ao ensino superior para alunos que não têm condições de pagar pelo ensino privado. ${ }^{2}$

Atualmente, a educação superior está organizada em diferentes enquadramentos (BRASIL, 2001b; 2006), seguindo critérios administrativos (públicas - federais, estaduais e municipais - e privadas - com e sem fins lucrativos/comunitárias, confessionais e filantrópicas), acadêmicos (universidades, universidades especializadas, centros universitários, Institutos Federais de Educação, Ciência e Tecnologia (Ifets), faculdades integradas, faculdades, institutos superiores de educação e centros de educação tecnológica) e formacionais (cursos de graduação - bacharéis, licenciados e tecnólogos, pós-graduação lato sensu e stricto sensu, extensão e sequenciais). Nessa nova composição, identificamos a ênfase na educação tecnológica nas possibilidades abertas pelos diferentes enquadramentos, sobretudo na instituição ou consolidação dos Ifets, que são instituições públicas especializadas na oferta de educação tecnológica em diversos níveis e modalidades, nos centros de educação tecnológica, que são instituições públicas ou privadas que oferecem educação em nível básico, técnico ou tecnológico em nível de escola secundária e de capacitação pedagógica para professores e especialistas e, em nível de formação, nos cursos tecnólogos.

\section{Os cursos superiores de tecnologia: a retomada e as novas confi- gurações}

O desenvolvimento da educação superior tecnológica, como vimos, tem suas raízes na reforma universitária de 1968, que deu origem aos cursos superiores de tecnologia e propôs a instalação e o funcionamento de cursos profissionais de curta 
duração, com habilitações intermediárias de grau superior (BRASIL, 2002a). Para Pereira (2008), esses cursos atendiam às necessidades de redução dos gastos do Estado com a educação universitária e ao anseio da crescente classe média brasileira.

No contexto das reformas educacionais da época, o Primeiro Plano Setorial de Educação e Cultura (1972-1974) do MEC previa incentivo especial ao nível superior de curta duração, por meio do projeto n. 19, que englobava também a formação do tecnólogo (AMARAL, 2006). Já com o projeto setorial n. 15, do Segundo Plano Setorial de Educação e Cultura (1975-1979), houve um empenho maior do MEC não apenas na criação e implantação de novos cursos superiores de tecnologia, mas também no incentivo a melhores condições de seu funcionamento, recomendando às instituições que os ofereciam que buscassem estreitar as relações com o mundo empresarial; a realização de uma rigorosa pesquisa de mercado de trabalho; a implantação dos cursos apenas em áreas profissionais demandadas pelas empresas; a diminuição do número de vagas e a desativação dos cursos quando houvesse saturação no mercado (BRASIL, 2002a). Entretanto, o que se observou foi que essas recomendações, na maioria das vezes, acabaram sendo desrespeitadas pelos estabelecimentos superiores de ensino, comprometendo os requisitos mínimos exigíveis para seu funcionamento com a qualidade requerida.

Os cursos superiores de tecnologia ganharam nova força com a nova LDB, sancionada em 1996, atendendo às demandas do mercado de trabalho e procurando adaptar as leis brasileiras às recomendações dos organismos multilaterais. A tendência foi criar no Brasil uma estrutura de oferta da educação superior com forte presença da iniciativa privada e com cursos superiores de curta duração, focados nas demandas dos setores da indústria e de serviços (PEREIRA, 2008), nos moldes da ideologia neoliberal dos anos de 1990 (SANTOS, 2005), portadora de novos padrões de produtividade e competitividade (MANFREDI, 2002). Esse foi um período em que as influências da globalização da economia se fizeram mais evidentes, com ações que têm como grande marca a flexibilização dos modelos de instituições de ensino e tipos de formação. Também as transformações tecnológicas, políticas e econômicas atingiram diretamente o mundo do trabalho e geraram mudanças, exigindo maior capacitação não apenas no que diz respeito aos conhecimentos formais, como também a um novo perfil do profissional, que para se inserir no mercado de trabalho precisa estar consciente da necessidade constante de aperfeiçoamento (GADOTTI, 2009).

O novo modelo de educação profissional e tecnológico, nesse sentido, traduz uma tentativa de adequar a educação às novas demandas sociais. A ideia é estruturar um tipo de formação que capacite o aluno e/ou trabalhador a empregar-se e manter-se em atividade. Assim, a educação entra em cena como condição para a concorrência no mercado de trabalho e como garantia para a melhoria das 
condições econômicas. A concepção implementada, nessa direção, é de que a educação do cidadão, de forma continuada, é fundamental para o desenvolvimento do país (BRASIL, 2002a).

A nova LDB deu outra dimensão aos cursos superiores de tecnologia e despertou o interesse por parte das instituições públicas e privadas. Reconheceu, ainda, o papel da educação profissional e sua articulação com todas as diferentes formas de educação, com o trabalho, com a ciência e a tecnologia, buscando conduzir ao permanente desenvolvimento das aptidões para a vida produtiva, garantindo aos cidadãos o direito à aquisição de competências profissionais que os habilitem em setores que utilizam novas tecnologias (idem, ibid.). Contudo, as diretrizes especificam que a educação de nível tecnológico requer muito mais que a formação técnica específica para um determinado fazer. Requer, além do domínio operacional de uma determinada técnica de trabalho, a compreensão global do processo produtivo, com a apreensão do saber tecnológico e do conhecimento que dá forma ao saber técnico e ao ato de fazer, com a valorização da cultura do trabalho e a mobilização dos valores necessários à tomada de decisões profissionais (ibid.).

Com a abertura propiciada pela LDB, e pelas legislações posteriores que tratam das instituições de ensino superior, verificou-se uma grande oferta de graduações tecnológicas nas mais variadas áreas, com diversas denominações e muitas vezes com perfis muito similares. Nestes termos, alguns autores sugerem que os Ifets representam um importante desafio para a educação profissional e tecnológica, visto que, ao se procurar romper com a tradicional missão de vincular essa modalidade da educação às demandas exclusivas do mercado, entra em cena a necessidade de construção de um novo paradigma para ela. Não se trata de preparar o cidadão para servir aos exclusivos interesses do mercado, como foi a tônica ao longo da história da educação profissional, mas de qualificá-lo e elevar o seu grau de escolarização, capitais imprescindíveis à efetiva participação na consolidação democrática do país (PACHECO et al., 2009). Identificamos, nessa direção, a primeira fase de expansão da rede federal, em 2005, pela criação de 64 novas unidades, orientadas por novas formas de regulação, supervisão e avaliação de instituições de educação superior e cursos superiores de graduação e sequenciais no sistema federal de ensino (BRASIL, 1994; 2005; 2006). Em 2007 foi lançada a segunda fase do projeto de expansão, com 150 novas unidades. Os centros federais de educação tecnológica (Cefets), as escolas técnicas federais, as escolas agrotécnicas federais e escolas técnicas vinculadas às universidades federais passaram a integrar a rede federal de educação tecnológica, pela constituição dos institutos federais de educação, ciência e tecnologia (Ifets). Identificamos que a criação e a expansão deste modelo institucional assegurou a ampliação da oferta de vagas gratuitas de nível superior, além de colaborar para a expansão do ensino superior tecnológico brasileiro. Atualmente, percebe-se o incentivo aos cursos 
superiores de tecnologia, cursos mais flexíveis/rápidos, para atender às necessidades do mercado, as quais decorrem do desenvolvimento tecnológico local e regional num determinado setor.

Pela análise documental ou observação de resultados, notamos a presença comum do conceito de educação profissional, de cursos e programas dirigidos para a obtenção de empregabilidade, sistemas flexíveis e modulares. Esses conceitos são centrais em todas as discussões sobre educação tecnológica, bem como trazem consigo a velha concepção de segmentação social, destinando processos educacionais distintos conforme a origem de classe. Se em tempos anteriores tal diretriz se prendia às próprias determinações da sociedade de classes, o que continua no presente, nos dias atuais a proposta parece também atender às determinações do mercado globalizado, no qual o país se insere como nação subalterna e periférica, dependente de ciência e tecnologia exógenas (LIMA FILHO, 1999).

Podemos dizer que, independentemente de uma educação profissional ou tecnológica, verifica-se a necessidade de uma formação humana em sua totalidade, integrando ciência, cultura, humanismo e tecnologia, visando ao desenvolvimento de todas as potencialidades humanas.

\section{A expansão dos cursos superiores de tecnologia: evidências recen- tes no Brasil}

Na última década verificou-se um aumento significativo na oferta de educação superior. Muitos centros universitários, faculdades, universidades, centros de educação tecnológica, faculdades de tecnologia, escolas e institutos superiores passaram a oferecer novas modalidades e novos cursos, frutos de alterações da legislação educacional e também dos novos contornos sociais e econômicos do país.

A partir dos dados obtidos do Inep, identificamos que a educação superior vem apresentando crescimento bastante expressivo, especialmente na oferta de cursos superiores de tecnologia, tanto que, no ano de 2010, existiam 4.775 cursos e eram ofertadas 541.166 vagas nesta modalidade de ensino. Os cursos de graduação presenciais, em geral, apresentaram crescimento no período de 2000 a 2010 (Tabela 1). Nos anos compreendidos entre 2001 a 2004 e 2009, vemos as maiores taxas de crescimento, tendência expansionista que se manteve posteriormente.

Essa realidade estende-se aos cursos superiores de tecnologia, que apresentaram crescimento na oferta e representam uma parcela significativa do total de cursos de graduação. Ao comparar os dados de 2000 e 2010, observamos que o número de cursos passou de 634, em 2000, para 4.775, em 2010 (um aumento de 1.211,8\%); o crescimento mais expressivo foi no ano de 2003 (80,1\%). 


\section{Tabela 1}

Distribuição do número total de cursos de graduação e dos cursos superiores de tecnologia, frequência absoluta e percentual de variação - Brasil: 2000 a 2010

\begin{tabular}{ccccc}
\hline Ano & $\begin{array}{c}\text { Total de } \\
\text { cursos de graduação }\end{array}$ & $\begin{array}{c}\text { \% de } \\
\text { variação }\end{array}$ & $\begin{array}{c}\text { Cursos } \\
\text { superiores de tecnologia }\end{array}$ & $\begin{array}{c}\text { \% de } \\
\text { variação }\end{array}$ \\
\hline 2000 & 10.576 & - & 364 & - \\
2001 & 12.155 & 14,9 & .446 & 22,5 \\
2002 & 14.396 & 18,4 & .634 & 42,2 \\
2003 & 16.438 & 14,2 & 1.142 & 80,1 \\
2004 & 18.653 & 13,5 & 1.804 & 58,0 \\
2005 & 20.412 & 9,4 & 2.525 & 40,0 \\
2006 & 22.105 & 8,3 & 3.037 & 20,3 \\
2007 & 23.488 & 6,3 & 3.702 & 21,9 \\
2008 & 24.719 & 5,2 & 4.355 & 17,6 \\
2009 & 27.827 & 12,6 & 4.491 & 3,1 \\
2010 & 28.577 & 2,7 & 4.775 & 6,3 \\
\hline
\end{tabular}

Fonte: Dados brutos do MEC/Inep/Censo da Educação Superior.

Ao correlacionar os cursos de graduação com os cursos superiores de tecnologia, verificamos que a oferta destes foi significativamente maior. Essa constatação vem ao encontro do entendimento de Ristoff e Giolo (2006), quando referem que a expansão dos cursos superiores de tecnologia intensificou-se a partir de 2000. A expansão da educação superior, para eles, não teve apenas sentido de ampliação geográfica, mas também de ampliação social, por meio do qual se incorporaram setores sociais antes excluídos desse grau de formação, ou seja, a classe média baixa e os trabalhadores foram atraídos, especialmente pelas instituições privadas, com cursos breves, mais baratos e com destinação profissional, abrindo espaço aos cursos superiores de tecnologia.

A Tabela 2 apresenta as evidências em termos de categoria administrativa e organização acadêmica $^{3}$ dos cursos superiores de tecnologia. Verificamos que os maiores percentuais de crescimento dos cursos superiores de tecnologia ocorreram em 2002 e 2005, especialmente no âmbito do setor privado e nas universidades, centros universitários e centros ou faculdades de tecnologia (CET/FAT). A oferta de cursos superiores de tecnologia no período de 2000 a 2010 apresentou uma tendência de expansão acelerada até 2003, quando atingiu o índice de crescimento de 80,1\% em relação a 2002; a partir de 2004, vemos um crescimento a taxas menores. 
Os cursos superiores de tecnologia no contexto de expansão da educação superior no Brasil...

\section{Tabela 2}

Distribuição do número de cursos superiores de tecnologia por categoria administrativa e organização acadêmica, frequência absoluta e percentual de variação - Brasil: 2000 a 2010

\begin{tabular}{|c|c|c|c|c|c|c|c|}
\hline \multicolumn{2}{|c|}{$\begin{array}{c}\text { Categoria } \\
\text { administrativa }\end{array}$} & \multirow{2}{*}{$\begin{array}{l}\begin{array}{l}\text { Total } \\
\text { IESs }\end{array} \\
115\end{array}$} & \multirow{2}{*}{$\begin{array}{c}\begin{array}{c}\text { Universi- } \\
\text { dades }\end{array} \\
30\end{array}$} & \multirow{2}{*}{$\begin{array}{c}\begin{array}{c}\text { Centros } \\
\text { Universitários }\end{array} \\
-\end{array}$} & \multirow{2}{*}{$\begin{array}{c}\text { Fac. } \\
\text { Integradas }\end{array}$} & \multirow{2}{*}{$\begin{array}{r}\begin{array}{c}\text { Faculda- } \\
\text { des }\end{array} \\
9\end{array}$} & \multirow{2}{*}{$\begin{array}{r}\mathrm{CET} / \mathrm{FaT} \\
75\end{array}$} \\
\hline Pública & 2000 & & & & & & \\
\hline & 2001 & 154 & 30 & - & 1 & 10 & 113 \\
\hline & 2002 & 213 & 42 & - & 1 & 6 & 164 \\
\hline & 2003 & 265 & 48 & 1 & 1 & 6 & 209 \\
\hline & 2004 & 359 & 81 & 1 & 1 & 7 & 269 \\
\hline & 2005 & 411 & 155 & 6 & 4 & 7 & 239 \\
\hline & 2006 & 477 & 186 & 7 & 4 & 3 & 277 \\
\hline & 2007 & 537 & 224 & 7 & 4 & 3 & 299 \\
\hline & 2008 & 582 & 248 & 10 & - & 74 & 250 \\
\hline & 2009 & 742 & 377 & 14 & - & 89 & 262 \\
\hline & 2010 & 805 & 323 & 14 & - & 155 & 313 \\
\hline \multicolumn{2}{|c|}{ Total $\% \Delta$ 2000-2010 } & 600,0 & 976,7 & $1.300,0$ & - & $1.622,2$ & 317,3 \\
\hline \multirow[t]{11}{*}{ Privada } & 2000 & 249 & 100 & 35 & 32 & 82 & - \\
\hline & 2001 & 292 & 99 & 46 & 35 & 82 & 30 \\
\hline & 2002 & 421 & 120 & 69 & 33 & 95 & 104 \\
\hline & 2003 & 877 & 393 & 141 & 45 & 118 & 180 \\
\hline & 2004 & 1.445 & 607 & 238 & 53 & 154 & 393 \\
\hline & 2005 & 2.114 & 801 & 363 & 73 & 320 & 557 \\
\hline & 2006 & 2.560 & 1.003 & 438 & 83 & 439 & 597 \\
\hline & 2007 & 3.165 & 1.199 & 563 & 120 & 678 & 605 \\
\hline & 2008 & 3.773 & 1382 & 725 & - & 1.666 & - \\
\hline & 2009 & 3.749 & 1351 & 751 & - & 1.647 & - \\
\hline & 2010 & 3.970 & 1388 & 760 & - & 1.822 & - \\
\hline \multicolumn{2}{|c|}{ Total $\% \Delta 2000-2010$} & $1.494,4$ & $1.288,0$ & $2.071,4$ & - & $2.122,0$ & - \\
\hline \multirow[t]{11}{*}{ Total CST } & 2000 & 364 & 130 & 35 & 33 & 91 & 75 \\
\hline & 2001 & 446 & 129 & 46 & 36 & 92 & 143 \\
\hline & 2002 & 634 & 162 & 69 & 34 & 101 & 268 \\
\hline & 2003 & 1.142 & 441 & 142 & 46 & 124 & 389 \\
\hline & 2004 & 1.804 & 688 & 239 & 54 & 161 & 662 \\
\hline & 2005 & 2.525 & 956 & 369 & 77 & 327 & 796 \\
\hline & 2006 & 3.037 & 1.189 & 445 & 87 & 442 & 874 \\
\hline & 2007 & 3.702 & 1.423 & 570 & 124 & 681 & 904 \\
\hline & 2008 & 4.355 & 1.630 & 735 & - & 1.740 & 250 \\
\hline & 2009 & 4.491 & 1.728 & 765 & - & 1.736 & 262 \\
\hline & 2010 & 4.775 & 1.711 & 774 & - & 1.977 & 313 \\
\hline \multicolumn{2}{|c|}{ Total $\% \Delta$ 2000-2010 } & $1.211,8$ & $1.216,2$ & $2.111,4$ & - & $2.072,5$ & 317,3 \\
\hline
\end{tabular}

Fonte: Dados brutos do MEC/Inep/Censo da Educação Superior. 
Percebemos que a evolução verificada ocorreu, sobretudo, no setor privado, uma vez que este, dos 4.775 cursos superiores de tecnologia existentes, ofertou em 2010 um total de 3.970 cursos, atingindo um percentual de crescimento de 1.494,4\%. O setor público, por sua vez, no mesmo período, teve um crescimento menos significativo, ofertando em 2010 apenas 805 cursos, o que representa uma expansão de $600,0 \%$ em relação aos 115 de 2000. Esse aumento no setor privado justifica-se em razão da ampliação das possibilidades de oferta de educação profissional de nível tecnológico prevista pela LDB e, de modo especial, na Lei n. 9.870/1999, ampliando-se, no cenário da educação superior, a presença de pessoas jurídicas com fins lucrativos. Assim, o setor privado viu nos cursos superiores de nível tecnológico uma grande oportunidade de negócio.

No panorama da educação superior apresentado por Ristoff e Giolo (2006), expansão e privatização aparecem intimamente relacionadas no país. Segundo os autores, é no período pós-LDB que se evidencia o enquadramento do sistema educacional às regras do mercado, com a busca crescente pela classe média baixa e por alguns setores populares do acesso à educação superior.

Avaliando a variação percentual de crescimento dos cursos superiores de tecnologia quanto à organização acadêmica, observamos que as universidades são as instituições que apresentam maior número de cursos (130 em 2000 e 1.711 cursos em 2010). Em termos percentuais, entretanto, o maior crescimento verificado foi nos centros universitários e nas faculdades (2.111,4\% e $2.072,5 \%$, respectivamente). A profusão mostrada pelas universidades e centros universitários pode ser interpretada, sobretudo, considerando-se a prerrogativa da autonomia que apenas essas modalidades detêm e por meio da qual podem criar, organizar e extinguir seus cursos superiores sem a interferência direta do MEC. Notamos que as faculdades e as faculdades integradas, que não detêm essa prerrogativa, apresentaram um percentual de crescimento menor no período.

Na distribuição da oferta de cursos superiores de tecnologia nas regiões brasileiras (Tabela 3), a Sudeste ganha destaque. As regiões Sul e Sudeste são as que ofertaram maior número de cursos no período: em 2010 eram 968 na região Sul e 2.653 na Sudeste. Porém, com relação ao percentual de crescimento, essas regiões foram as que apresentaram menor crescimento: $796,3 \%$ e $1.289,0 \%$, respectivamente. A região Nordeste foi a que apresentou maior crescimento, chegando a $2.108,3 \%$, ou seja, passou de 24 cursos ofertados em 2000 para 530 no ano de 2010. As regiões Norte e Centro-Oeste também tiveram crescimento expressivo, 1.475,0\% e 1.388,0\%, com um total de cursos, em 2010, de 252 (Norte) e 372 (Centro-Oeste). Entretanto, quanto ao número de cursos ofertados, a situação se inverte, visto que a região Sudeste é a que apresenta maior número, seguida pelas regiões Sul, Nordeste, CentroOeste e Norte. 


\section{Tabela 3}

Distribuição do número de cursos superiores de tecnologia, por região - Brasil: 2000 a 2010

\begin{tabular}{c|crrrrrrrrrr}
\hline \multirow{2}{*}{ Ano } & \multicolumn{2}{c}{ Centro-Oeste } & \multicolumn{2}{c}{ Nordeste } & \multicolumn{2}{c}{ Norte } & \multicolumn{2}{c}{ Sudeste } & \multicolumn{2}{c}{ Sul } \\
\cline { 2 - 11 } & Cursos & $\% \Delta$ & Cursos & $\% \Delta$ & Cursos & $\% \Delta$ & Cursos & $\% \Delta$ & Cursos & $\% \Delta$ \\
\hline 2000 & 25 & - & 24 & - & 16 & - & 191 & - & 108 & - \\
2001 & 40 & 60,0 & 38 & 58,3 & 19 & 18,8 & 231 & 20,9 & 118 & 9,3 \\
2002 & 46 & 15,0 & 76 & 100,0 & 31 & 63,2 & 349 & 51,1 & 132 & 11,9 \\
2003 & 75 & 63,0 & 135 & 77,6 & 57 & 83,9 & 667 & 91,1 & 208 & 57,6 \\
2004 & 118 & 57,3 & 188 & 39,3 & 87 & 52,6 & 1068 & 60,1 & 343 & 64,9 \\
2005 & 210 & 78,0 & 251 & 33,5 & 110 & 26,4 & 1464 & 37,1 & 490 & 42,9 \\
2006 & 250 & 19,0 & 340 & 35,5 & 132 & 20,0 & 1738 & 18,7 & 577 & 17,8 \\
2007 & 310 & 24,0 & 350 & 2,9 & 185 & 40,2 & 2140 & 23,1 & 717 & 24,3 \\
2008 & 347 & 11,9 & 442 & 26,3 & 216 & 16,8 & 2163 & 1,1 & 852 & 18,8 \\
2009 & 355 & 2,3 & 457 & 3,4 & 263 & 21,8 & 2498 & 15,5 & 918 & 7,7 \\
2010 & 372 & 4,8 & 530 & 16,0 & 252 & $-4,2$ & 2653 & 6,2 & 968 & 5,4 \\
Total \% $\Delta$ & $2000-2010$ & $1.388,0$ & $-2.108,3$ & $-1.475,0$ & - & $1.289,0$ & - & 796,3 \\
\hline
\end{tabular}

Fonte: Dados brutos do MEC/Inep/Censo da Educação Superior.

Assim, como comentam Santos e Silveira (2001), a localização das demandas educacionais por maior qualificação da força de trabalho é condicionada pela desigual constituição técnica do território nacional e pelo modo de desenvolvimento das relações sociais de produção presentes em cada região. Para os autores, a necessidade do maior nível educacional para a população, ao seguir o novo paradigma produtivo, apresenta-se com maior vigor nas regiões onde se encontram as formas de produção mais desenvolvidas no Brasil: Sul e Sudeste, manifestando-se com menos intensidade no restante do território nacional.

Considerando os 4.775 cursos superiores de tecnologia ofertados em 2010 e a distribuição desses pelas diferentes organizações acadêmicas, podemos observar (Figura 1) que, nesse ano, mais de 50\% dos cursos ofertados se concentravam em apenas dez áreas. A administração e suas respectivas habilitações ocupam a primeira posição no ranking, ofertando 1.445 cursos em 2010. Outra área que chama atenção é a da informática, por meio dos cursos de Processamento de Dados e Ciência da Computação e seus correlatos, somando 788 cursos. Os dados mostram uma concentração em cursos nos quais geralmente são exigidos poucos investimentos iniciais e demandados pelo desenvolvimento tecnológico e pela sociedade da informação. 


\section{Figura 1}

Distribuição do número de cursos superiores de tecnologia por área do conhecimento - Brasil: 2010

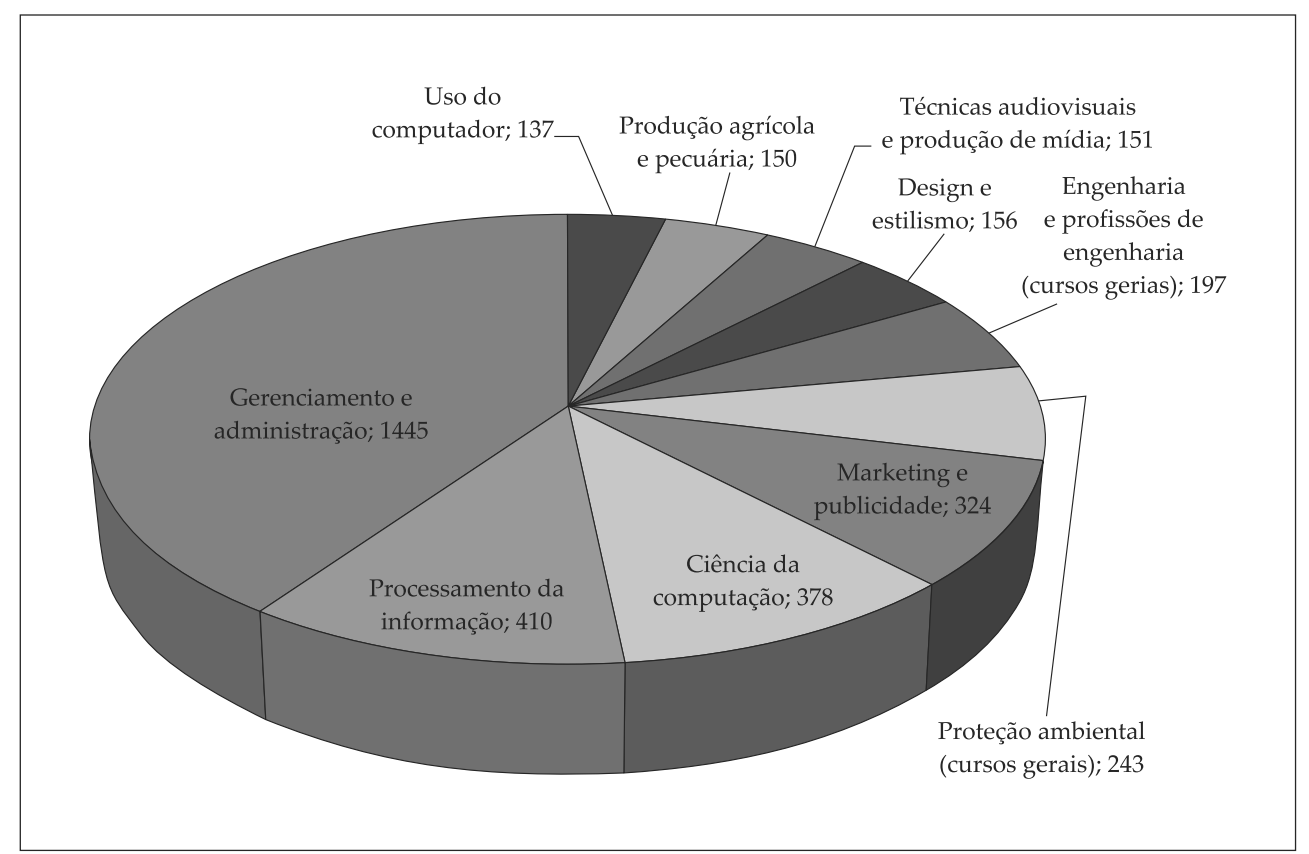

Fonte: Dados brutos do MEC/Inep/Censo da Educação Superior.

Entretanto, segundo Pereira (2008), o que vem acontecendo é a criação de cursos de menor duração, voltados para demandas pontuais e específicas do mercado de trabalho, que em nada contribuem para atingir o objetivo de formar pessoas capazes de inovar nas ciências e na tecnologia; ao contrário, acabam por formar mão de obra em massa para atividades que não requerem conhecimento conceitual aprofundado.

De outra parte, mais expressivos que os percentuais de crescimento ostentados pela oferta de cursos, foram os dados relativos às vagas oferecidas. A oferta de vagas nos cursos superiores de tecnologia somava, em 2010, um total de 541.166, contra 34.609 vagas em 2000, um aumento de 93,6\%. As maiores taxas de crescimento identificadas foram nos anos de 2002 (60,9\%), 2003 (89,3\%), 2004 (60,7\%) e 2005 (30,9\%); a partir deste ano as taxas de crescimento diminuíram gradativamente. No que tange à categoria administrativa, as vagas oferecidas pelo setor privado aumentaram $94,8 \%$ no período, ao passo que no setor público aumentaram em 342,8\%. Em termos absolutos, entretanto, o setor privado é responsável por 13,2 vezes o número de vagas de cursos de tecnologia oferecidas pelo setor público.

Do ponto de vista da organização acadêmica, as faculdades foram as que mais ofertaram vagas nos cursos superiores de tecnologia, totalizando 245.644 em 2010, 
um número muito superior ao das demais organizações, universidades, centros universitários e centros ou faculdades de tecnologia (CET/FAT), que, no mesmo ano, ofertaram 170.531, 111.729 e 13.262, respectivamente. Em termos de variação relativa, os valores mais expressivos foram obtidos, também, pelas faculdades $(2.698,1 \%)$, seguidos pelas universidades $(1.795,0 \%)$ e pelos centros universitários $(1.550,4 \%)$; nos CET/FaT apresentaram um crescimento menos expressivo (98,9\%). Notamos, nesse sentido, que os centros universitários foram a modalidade de organização acadêmica que manteve taxas de crescimento semelhantes anualmente; as demais organizações apresentaram, em alguns anos, taxas de variação negativa.

\section{Considerações finais}

Este estudo buscou evidenciar a expansão e o comportamento da oferta dos cursos superiores de tecnologia no âmbito do sistema de educação brasileiro, no período posterior à Lei de Diretrizes e Bases da Educação (LDB/1996). Para melhor compreender esse cenário foram analisadas as políticas que deram suporte ao desenvolvimento histórico da educação profissional.

Durante os últimos anos, presenciou-se um grande incentivo à educação profissional e tecnológica de nível superior, tanto em termos de legislação brasileira quanto no discurso da opinião pública. A oferta dessa modalidade de curso pautou-se pela flexibilidade, rapidez e praticidade e tem uma forte participação da iniciativa privada, que foi a rede que mais se mobilizou e se expandiu nessa oferta. Percebemos que as denominadas tecnologias, as mudanças sociais, econômicas e, sobretudo, a criação de novos produtos e mercados criaram a necessidade de uma maior qualificação do trabalhador. É nessa perspectiva que os cursos superiores de tecnologia podem se constituir como uma importante forma de capacitação em nível superior para os trabalhadores.

Avaliando os dados secundários tratados, podemos afirmar que os cursos superiores de tecnologia se expandiram rapidamente no período de 2000 a 2010, principalmente no setor privado de ensino. Entre 2000 e 2007, as universidades foram as organizações acadêmicas que mais apresentaram crescimento no período, seguidas dos CET/FAT, que a partir da implantação do programa de expansão da rede federal de educação profissional, científica e tecnológica passaram a ofertar cursos de nível superior, contribuindo, significativamente, para sua expansão. No período como um todo, todavia, a expansão foi maior nos centros universitários e faculdades.

No que tange à expansão territorial, os dados revelam que houve crescimento significativo em todas as regiões brasileiras. Contudo, a região Sudeste chama a atenção pelo grande número de cursos e vagas ofertadas, fato que pode ser justificado pela hegemonia econômica e populacional da região. 
Apesar da expansão e dos números ainda positivos, identificamos pelo estudo que o ritmo de crescimento desses cursos tem diminuído, principalmente a partir de 2004. Ainda que a tendência seja aproximar o perfil dos cursos às necessidades imediatas do mercado, o setor tem lidado com uma progressiva e expressiva ociosidade e com um elevado índice de evasão. A razão principal disso pode estar relacionada à situação econômica das famílias pertencentes às camadas populares da sociedade, fato que aponta a direção que a expansão deve tomar: o da oferta pública. As políticas educacionais dos últimos anos andam nessa direção. Resta saber em que medida a expansão pública conseguirá reverter a tendência de privatização do sistema observada no período pós-LDB. O grande desafio que se apresenta hoje é desenvolver uma educação tecnológica capaz de articular uma formação completa, envolvendo "educação, trabalho, ciência e tecnologia".

Para finalizar, sugerimos duas possibilidades de encaminhamentos para serem aprofundadas em futuras investigações sobre os cursos superiores de tecnologia, no que se refere a ofertas de cursos e vagas nas diferentes regiões brasileiras e ao porquê dessas diferenças regionais, sobretudo no setor privado. A primeira sugere que o quadro geral apresentado precisa ser fundamentado com pesquisas locais e regionais que busquem compreender as razões dos diferentes níveis de desenvolvimento nas regiões do país. A segunda indica a oportunidade de investigar as motivações que desencadearam iniciativas para expandir a educação tecnológica, as razões dos diferentes ritmos de expansão, de retração e também da evasão.

\section{Notas}

1. O Sinaes, instituído pela Lei n. 10.861/04, entre outras medidas, substituiu o "Provão" (Lei n. 9.131/95) pelo Exame Nacional de Cursos (Enade).

2. Um desses é o Programa Universidade para Todos (Prouni), criado pela Lei n. 11.096/05, que concede bolsas de estudos integrais ou parciais para estudantes de cursos de graduação em instituições privadas de ensino.

3. A partir do ano de 2008, os dados disponibilizados pelo Inep/MEC tiveram uma alteração na apresentação por organização acadêmica, o que pode ser visualizado nos dados apresentados para o período. Na rede privada, as categorias passaram a ser subdividas em: Universidades, Centros Universitários e Faculdades, sendo que esta abrange as Faculdades, as Faculdades Integradas e as Faculdades de Tecnologia. Já na rede pública as categorias se subdividem em: Universidades, Centros Universitários, Centros Federais de Educação Tecnológica e Faculdades, esta abrangendo as Faculdades, as Faculdades de Tecnologia e as Faculdades Integradas.

\section{Referências}

AMARAL, C.T. Políticas para a formação do tecnólogo realizado em um curso de gestão empresarial. 2006. 256f. Dissertação (Mestrado em Educação) - Universidade Católica de Minas Gerais, Belo Horizonte. 
BRASIL. Constituição (1988). Constituição da República Federativa do Brasil. Brasília, DF: Senado Federal, 1988.

BRASIL. Lei n. 4.024, de 20 de dezembro de 1961. Fixa as Diretrizes e Bases da Educação Nacional. Diário Oficial da União, Brasília, DF, 27 dez 1961.

BRASIL. Lei n. 5.540, de 28 de novembro de 1968. Fixa normas de organização e funcionamento do ensino superior e sua articulação com a escola média, e dá outras providências. Diário Oficial da União, Brasília, DF, 23 nov 1968.

BRASIL. Lei n 6.545, de 30 de junho de 1978. Dispõe sobre a transformação das Escolas Técnicas Federais de Minas Gerais, do Paraná e Celso Suckow da Fonseca em Centros Federais de Educação Tecnológica e dá outras providências. Diário Oficial da União, Brasília, DF, 4 jul 1978.

BRASIL. Decreto n. 97.333, de 21 de dezembro de 1988. Autoriza o funcionamento do Curso Superior de Tecnologia em Hotelaria do Instituto Superior de Hotelaria e Turismo. Diário Oficial da União, Brasília, DF, 22 dez 1988.

BRASIL. Lei n 8.948, de 8 de dezembro de 1994. Dispõe sobre a instituição do Sistema Nacional de Educação Tecnológica e dá outras providências. Diário Oficial da União, Brasília, DF, 9 dez 1994.

BRASIL. Lei n. 9.394, de 20 de dezembro de 1996. Lei de Diretrizes a Bases da Educação. Diário Oficial da União, Brasília, DF, 23 dez 1996.

BRASIL. Portaria n. 1.647, de 25 de novembro de 1999. Dispõe sobre o credenciamento de centros de educação tecnológica e a autorização de cursos de nível tecnológico da educação profissional. Brasília, DF: Ministério da Educação, 1999a.

BRASIL. Resolução CNE/CEB n. 4, de 8 de novembro de 1999. Institui as Diretrizes Curriculares Nacionais para a Educação. Diário Oficial da União, Brasília, DF, 1999b.

BRASIL. Parecer CNE/CES n. 436, de 5 de abril de 2001. Trata de cursos superiores de tecnologia: formação de tecnólogos. Diário Oficial da União, Brasília, DF, 6 abr 2001a.

BRASIL. Decreto n. 3.860, de 9 de julho de 2001. Dispõe sobre a organização do ensino superior, a avaliação de cursos e instituições, e dá outras providências. Diário Oficial da União, Brasília, DF, 10 jul. $2001 b$.

BRASIL. Resolução CNE/CP n. 3, de 18 de dezembro 2002. Institui as diretrizes curriculares nacionais gerais para a organização e o funcionamento dos cursos superiores de tecnologia. Brasília, DF: CNE/CP, 2002.

BRASIL. Parecer CNE/CP n. 29, de 3 de dezembro de 2002. Trata das diretrizes curriculares nacionais no nível de tecnólogo. Diário Oficial da União, Brasília, DF, 2002a. 
BRASIL. Decreto n. 5.154, de 23 de julho de 2004. Regula o parágrafo $2^{\circ}$ do artigo 36 e os artigos 39 a 41 da Lei n. 9.394, de 20 de dezembro de 1996. Diário Oficial da União, Brasília, DF, 26 jul 2004.

BRASIL. Decreto n. 5.205, de 14 de setembro de 2004. Regulamenta a Lei n. 8.958, de 20 de dezembro de 1994, que dispõe sobre as relações entre as instituições federais de ensino superior e de pesquisa científica e tecnológica e as fundações de apoio. Diário Oficial da União, Brasília, DF, 15 set 2004b.

BRASIL. Decreto n. 5.224, de 1 de outubro de 2004. Dispõe sobre a organização dos Centros Federais de Educação Tecnológica e dá outras providências. Diário Oficial da União, Brasília, DF, 04 out 2004a.

BRASIL. Lei n. 10.973, de 2 de dezembro de 2004. Regulamento Dispõe sobre incentivos à inovação e à pesquisa científica e tecnológica no ambiente produtivo e dá outras providências. Diário Oficial da União, Brasília, DF, 3 dez 2004c.

BRASIL. Lei n. 11.195, de 18 de novembro de 2005. Dá nova redação ao $\S 5^{\circ}$ do art. $3^{\circ}$ da Lei n. 8.948, de 8 de dezembro de 1994. Diário Oficial da União, Brasília, DF, 18 nov 2005.

BRASIL. Decreto n. 5.773, de 9 de maio de 2006. Dispõe sobre o exercício das funções de regulação, supervisão e avaliação de instituições de educação superior e cursos superiores de graduação e seqüenciais no sistema federal de ensino. Diário Oficial da União, Brasília, DF, 10 maio 2006.

BRASIL. Lei n. 11.892, de 29 de dezembro de 2008. Institui a Rede Federal de Educação Profissional, Científica e Tecnológica, cria os Institutos Federais de Educação, Ciência e Tecnologia, e dá outras providências. Diário Oficial da União, Brasília, DF, 29 dez 2008.

BRASIL. Ministério da Educação. Centenário da Rede Federal de Educação Profissional e Tecnológica. Brasília, DF: MEC/Setec, 2009b. Disponível em: <http://portal.mec.gov.br/ setec/arquivos/centenario/historico_educacao_profissional.pdf >. Acesso em: 10 nov. 2009.

CHRISTOPHE, M. A legislação sobre a educação tecnológica, no quadro da educação profissional brasileira. 2005. Disponível em: http://www.iets.org.br/biblioteca/A_legislacao_ sobre_a_educacao_tecnologica.pdf. Acesso em: 3 jun. 2010.

CUNHA, L.A. A universidade reformada. Rio de Janeiro: Francisco Alves, 1988.

GADOTTI, M. Educação e globalização neoliberal: um olhar a partir da América Latina. Educação \& Linguagem, São Paulo, v. 1, p. 62-78, 2009.

KUENZER, A.Z. A reforma do ensino técnico no Brasil e suas consequências. Ensaio: Políticas Públicas em Educação, Rio de Janeiro, v. 6, n. 20, p. 365-384. jul./set. 1995. 
LIMA FILHO, D.L. Formação de tecnólogos: lições da experiência, tendências atuais e perspectivas. Boletim Técnico do SENAC, São Paulo, v. 25, n. 3, 1999. Disponível em: $<$ www.senac.br/informativo/bts/253/boltec253d.htm>. Acesso em: 1 jun. 2009.

MANFREDI, S.M. Educação profissional no Brasil. São Paulo: Cortez, 2002.

NEVES, C.E.B. Universidade brasileira: equidade, qualidade e cidadania. Coimbra, 2004. Disponível em: $<$ http://www.ces.uc.pt/lab2004/inscricao/pdfs/painel44/ClarissaNeves. pdf $>$. Acesso em: 10 abr. 2008.

PACHECO, E.M. (Org.). Os institutos federais: uma revolução profissional e tecnológica. Brasília, DF: Fundação Santillana; São Paulo: Moderna, 2011. Disponível em: <http:// portal.mec.gov.br/setec/arquivos/pdf/insti_evolucao.pdf $>$. Acesso em: 8 abr. 2009.

PACHECO, E.M. et al. Educação profissional e tecnológica: das Escolas de Aprendizes Artífices aos Institutos Federais de Educação, Ciência e Tecnologia. TEC Amazônia, Manaus, v. 7, n. 16, p. 1-7, 2009.

PEREIRA, F. (Im)possibilidades da construção de uma educação emancipadora em cursos tecnológicos: uma abordagem a partir de dois cursos localizados em Goiânia e Anápolis/ Francisco Pereira. 2008. 200f. Dissertação (Mestrado em Educação) - Universidade Católica de Goiás, Goiânia.

RISTOFF, D.; GIOLO, J. (Org.). Educação superior brasileira: 1991-2004. Brasília, DF: MEC/INEP, 2006.

ROSSATO, R. Universidade em reforma. Espaço Pedagógico, Passo Fundo, v. 11, n. 1, p. 20-34, jan.jjun 2004.

ROSSATO, R. Universidade: nove séculos de história. 2. ed. Passo Fundo: UPF, 2005.

SANTOS, B.S. A universidade do século XXI: para uma reforma democrática e emancipatória da Universidade. Educação, Sociedade e Culturas, Porto, v. 23, p.137-202, 2005. Disponível em: <http://www.ces.uc.pt/bss/documentos/auniversidadedosecXXI.pdf>. Acesso em: 14 jun. 2010.

SANTOS, M.; SILVEIRA, M. O Brasil: território e sociedade no início do século XXI. São Paulo; Rio de Janeiro: Record, 2001.

SUBIRATS, M. A educação do século XIX: a urgência de uma educação moral. In IMBERNÓN, F. (Coord.). A educação no século XXI: os desafios do futuro imediato. Porto Alegre: Artmed, 2000.

Recebido em 22 de julho de 2011.

Aprovado em 13 de dezembro de 2012. 